\title{
Effects of supervised exercise on cancer-related fatigue in breast cancer survivors: a systematic review and meta-analysis
}

\author{
José Francisco Meneses-Echávez ${ }^{1 *}$, Emilio González-Jiménez² and Robinson Ramírez-Vélez
}

\begin{abstract}
Background: Cancer-related fatigue (CRF) is the most common and distressing symptom in breast cancer survivors. Approximately $40 \%$ to $80 \%$ of cancer patients undergoing active treatment suffer from CRF. Exercise improves overall quality of life and CRF; however, the specific effects of the training modalities are not well understood.

Methods: This study aimed to determine the pooled effects of supervised exercise interventions on CRF in breast cancer survivors. We searched PubMed/MEDLINE, EMBASE, Scopus, CENTRAL and CINAHL databases between December 2013 and January 2014 without language restrictions. Risk of bias and methodological quality were evaluated using the PEDro score. Pooled effects were calculated with a random-effects model according to the DerSimonian and Laird method. Heterogeneity was evaluated with the $\mathrm{I}^{2}$ test.

Results: Nine high-quality studies $(n=1156)$ were finally included. Supervised aerobic exercise was statistically more effective than conventional care in improving CRF among breast cancer survivors ( $S M D=-0.51,95 \% \mathrm{Cl}-0.81$ to -0.21 ), with high statistical heterogeneity $\left(P=0.001 ;\left.\right|^{2}=75 \%\right)$. Similar effects were found for resistance training on CRF $\left(\mathrm{SMD}=-0.41,95 \% \mathrm{Cl}-0.76\right.$ to $\left.-0.05 ; P=0.02 ;\left.\right|^{2}=64 \%\right)$. Meta-regression analysis revealed that exercise volume parameters are closely related with the effect estimates on CRF. Egger's test suggested moderate evidence of publication bias $(P=0.04)$.
\end{abstract}

Conclusions: Supervised exercise reduces CRF and must be implemented in breast cancer rehabilitation settings. High-volume exercises are safe and effective in improving CRF and overall quality of life in women with breast cancer. Further research is encouraged.

Trial Registration: CRD42014007223

Keywords: Breast Neoplasms, Exercise, Resistance training, Rehabilitation, Medical oncology

\section{Background}

Breast cancer is the most common cancer in women worldwide [1,2]. Breast cancer is also a leading cause of cancer death among women, accounting for $23 \%$ of total cancer cases and 14\% of cancer deaths [3]. The World Health Organization (WHO) [4] estimated that breast cancer incidence in South America was 114,898 cases in 2008. In Colombia, nearly 5,000 new cases are diagnosed annually [5]. However, due to significant improvements in screening protocols, diagnosis, and treatment over the

\footnotetext{
*Correspondence: menesesjose77@gmail.com

'Grupo GICAEDS. Facultad de Cultura Física, Deporte y Recreación,

Universidad Santo Tomás, Bogotá, D.C, Colombia

Full list of author information is available at the end of the article
}

past few decades, breast cancer mortality has progressively decreased $[6,7]$.

Cancer-related fatigue (CRF) is the most common and devastating symptom in breast cancer patients during and after therapeutic treatment [8]. Breast cancer patients continue to experience fatigue symptoms for months or years after successful treatment. Stone and colleagues observed that $75 \%$ of patients with various solid tumors (among whom 48 of 95 had metastatic disease) had a significantly increased cancer-related fatigue score compared with a matched control population [9]. It has been suggested that CRF might be considered a strong predictor of lower survival for cancer patients [10]. 
Exercise is widely recognized as an effective nonpharmacological therapy in cancer patients [11-13]. A growing body of evidence supports the idea that increasing physical activity provides important benefits to promote psychological outcomes and physical well-being in cancer patients [13-16]. These symptoms have been associated with clinical-related outcomes in breast cancer patients receiving active treatment regimens [11,13,17-24]. Some systematic reviews have communicated ambiguous findings concerning the effects of exercise interventions on CRF [11-13,15-22]. A recent Cochrane systematic review about exercise and CRF [17] concluded that aerobic exercise reduces CRF and encouraged further research of other exercise modalities. However, that review only included data published by March 2011 and did not examine supervised physical activity interventions in isolation from unsupervised interventions. A recent prospective randomized pilot trial by Oechsle et al. [25] reported that supervised exercise improved fatigue symptoms in 48 patients receiving myeloablative chemotherapy during the hospitalization period for chemotherapy. Nonetheless, the optimal doses and modes of exercise have not been addressed [26-28], yet these issues are essential to reach a more complete understanding of CRF control through supervised exercise training. In light of these gaps in the literature, this systematic review aimed to determine the pooled effects of supervised exercise interventions on CRF in breast cancer survivors, via a meta-analysis of randomized controlled trials.

\section{Methods}

\section{Protocol and objective}

This systematic review was conducted and reported in accordance with the Preferred Reporting Items for Systematic Reviews and Meta-Analyses (PRISMA) Statement [29] (PROSPERO Register code: CRD42014007223). No funding support was received in this study.

\section{Search methods}

Two blinded authors (JFM-E and RR-V) independently applied the search strategy between December 2013 and January 2014. The electronic databases (PubMed/MEDLINE, EMBASE, Scopus, CENTRAL and CINAHL) databases were systematically searched by combining Boolean operators and any of the following search terms: "breast cancer", "cancer-related fatigue" and "exercise". (See Appendix 1 for further details). The authors incorporated the recommendations of Robinson and Dickersin [30] to achieve a highly sensitive search strategy for the retrieval of clinical trials on PubMed. The title and abstract were examined and full text was obtained if there was ambiguity regarding eligibility. In addition, the authors examined the reference lists of the identified records and the conference abstracts of the American Society of Clinical Oncology (ASCO) Annual Meeting on its website from 2004 to 2013, as well as certain journals (i.e., The Lancet Oncology, Journal of Clinical Oncology, Journal of the National Cancer Institute, Journal of Breast Cancer, The Breast Journal, and The Breast). No language restrictions were applied. Attempts were made to contact authors of trial reports if clarification was necessary.

\section{Ethics proclamations}

This systematic review and meta-analysis included experimental studies that followed the provisions stated in the Declaration of Helsinki and were approved by the Ethics Committee. All patients signed informed consent. One author (JFM-E) performed this verification.

\section{Selection criteria}

After screening the search results, two blinded authors (JFM-E and EGJ) independently evaluated eligibility of all studies retrieved from the databases based on the selection criteria. The studies were included if they met the following criteria according to the Patient/Problem, Intervention, Comparison/Control or Comparator and Outcomes/ Effects (PICO) methodology [29].

We included randomized controlled trials involving breast cancer survivors without restrictions to a particular stage of disease. Systematic reviews, editorials, crosssectional studies, case reports and case series studies were excluded. We performed a subgroup analysis according to the stage of treatment for those studies involving participants during or after therapeutic anticancer treatment. Supervised exercise interventions were included in the systematic review, while non-supervised exercise programs were excluded. Exercise interventions were evaluated according to the definition of physical activity provided by Wolin et al. [31], "as any body movement causing an increase in energy expenditure that involves a planned or structured movement of the body performed in a systematic manner in terms of frequency, intensity, and duration and is designed to maintain or enhance health-related outcomes". Therefore, tai-chi, manual therapy (joint mobilization techniques and therapeutic massage) and cognitive-behavioral interventions were excluded due to excessive variation in their mode, frequency, duration and intensity. Conventional care was considered a comparison group, and this group included women who did not participate in any exercise intervention program. Studies that compared supervised exercise with pharmacological and surgical treatments were excluded. Disagreements were resolved by consensus and the participation of a third author (RRV).

\section{Data extraction and quality assessment}

Two authors (JFM-E and RRV) independently performed data extraction. Relevant data were extracted to a computer-based spreadsheet. The reviewers extracted 
the following information: authors' information, publication year, study design, cancer treatment, time since diagnosis and characteristics of the exercise interventions (mode of training, length, duration and frequency) and effect estimates.

The methodological quality of the studies, including their risk of bias, was assessed using the PEDro scale, which is based on the Delphi list [32]. The PEDro scale scores the methodological quality of randomized trials out of 10. The score for each included study was determined by a trained assessor (JFM-E). Scores were based on all information available from both the published version and from communication with the authors. A score of 5 of 10 was set as the minimum score for inclusion in the current meta-analysis [33]. Three authors (JFM-E, RRV and EGJ) independently performed this assessment.

\section{Outcome measures}

Cancer-related fatigue (CRF) was the primary outcome measure. The National Comprehensive Cancer Network (NCCN) [34] defines CRF as "a distressing, persistent, subjective sense of physical, emotional and/or cognitive tiredness or exhaustion related to cancer or cancer treatment that is not proportional to recent activity and interferes with usual functioning." We considered the following validated tools for the measurement of fatigue levels: the Functional Assessment of Cancer Therapy (FACT)-Fatigue Scale, European Organization for Research and Treatment of Cancer Quality of Life Questionnaire (EORTC QLQC30), Piper Fatigue Scale (PFS), Schwartz Cancer Fatigue Scale (SCFS) and the Multidimensional Fatigue Inventory (MFI). Furthermore, we considered the following secondary outcome measures: depression; body mass index (BMI) as an indicator of body composition closely related to cancer progression; physical activity levels (minutes per week); and quality of life including physical, social, emotional and functional well-being. Pooled analysis for secondary outcomes was carried out if at least two studies were available for the outcome.

\section{Data synthesis}

All statistical analyses were conducted using Comprehensive Meta-Analysis and Review Manager Software [35], developed by the Cochrane Collaboration. CRF was reported as continuous data. Therefore, we recorded both the mean change from baseline for each group or the mean post-intervention and standard deviation. Considering that different scales were used for the outcome measurements, we calculated standardized mean differences (SMD) with 95\% confidence intervals (CI). If standard deviations were not reported, they were estimated through standard errors (CI or $t$ values) [36]. SMDs were significant if their 95\% CIs excluded zero. When high heterogeneity $\left(\mathrm{I}^{2}>50 \%\right)$ was detected, the pooled effects were calculated by using a random-effects model reported in accordance with the DerSimonian and Laird method, which considers both within-study and between-study differences [36]. On the contrary, if substantial heterogeneity was not detected, we conducted a fixed-effects model reported by using the inverse variance method [36].

Statistical heterogeneity of the effect estimates among studies was assessed using $\mathrm{I}^{2}$ statistic which estimates the percentage of total variation across studies that was attributable to heterogeneity rather than to chance [37]; values greater than $50 \%$ were considered indicative of high heterogeneity. We performed a meta-regression analysis to explore the predictor effects of the supervised exercise characteristics, such as length (weeks), frequency (sessions per week), and duration (minutes per session) on the effect estimates. Publication bias was evaluated with the Egger's test [36]. Two-sided $P$ values of less than 0.05 were considered statistically significant.

\section{Results}

\section{Characteristics of the studies included}

Nine studies [38-46] $(n=1156)$ were included in the systematic review and meta-analysis. The assessment of risk of bias showed a mean PEDro score of 6.33 (SD = 1.1), indicating consistent methodological quality and a low risk of most biases (Table 1). The mean publication year for the included studies was $2008(\mathrm{SD}=4.5)$, and most were conducted in North America $(k=3)$, United Kingdom, Finland, Australia and Turkey. Figure 1 presents the PRISMA flow diagram.

\section{Characteristics of breast cancer survivors}

The mean age of participants in the included studies ranged from 48 to 60 years with an average of 55.2 years old $(\mathrm{SD}=4.1)$. Breast cancer survivors were predominately non-Hispanic whites. Supervised exercise training groups comprised a total of 556 breast cancer survivors, and 460 women were allocated to control groups. Sixtyseven percent ( $n=6$ studies) [38,40,42-45] of the studies were conducted during active treatment, including chemotherapy and radiotherapy regimens. Regarding treatment descriptions, 638 participants received chemotherapy, and 510 received radiotherapy. The studies rarely reported time since diagnosis. Table 2 summarizes the characteristics of the studies included.

\section{Characteristics of supervised exercise interventions}

Aerobic training was prescribed in all trials $(n=9)$ [38-46], six of which included resistance training $[38,39,41-43,46]$. Stretching exercises were performed in one study [42]. Supervised exercise interventions had a mean length of 21.4 weeks (SD 15.8) with a mean duration of 44.3 minutes (SD 15.2) and an average of 2.5 
Table 1 Assessment of methodological quality and risk of bias with PEDro scale

\begin{tabular}{|c|c|c|c|c|c|c|c|c|c|c|c|}
\hline Study & $\begin{array}{l}\text { Random } \\
\text { allocation }\end{array}$ & $\begin{array}{l}\text { Concealed } \\
\text { allocation }\end{array}$ & $\begin{array}{l}\text { Groups similar } \\
\text { at baseline }\end{array}$ & $\begin{array}{l}\text { Participant } \\
\text { blinding }\end{array}$ & $\begin{array}{l}\text { Therapist } \\
\text { blinding }\end{array}$ & $\begin{array}{l}\text { Assessor } \\
\text { blinding }\end{array}$ & $\begin{array}{l}<15 \% \\
\text { dropouts }\end{array}$ & $\begin{array}{l}\text { Intention to } \\
\text { treat analysis }\end{array}$ & $\begin{array}{l}\text { Between-group } \\
\text { difference reported }\end{array}$ & $\begin{array}{l}\text { Point estimate and } \\
\text { variability reported }\end{array}$ & $\begin{array}{l}\text { Total }(0 \\
\text { to } 10)\end{array}$ \\
\hline $\begin{array}{l}\text { Campbell et al. } \\
2005 \text { [38] }\end{array}$ & Y & N & Y & $\mathrm{N}$ & N & $\mathrm{N}$ & Y & $\mathrm{N}$ & Y & Y & 5 \\
\hline $\begin{array}{l}\text { Cantarero et al. } \\
2013 \text { [39] }\end{array}$ & Y & Y & Y & $\mathrm{N}$ & N & Y & Y & $N$ & Y & Y & 7 \\
\hline $\begin{array}{l}\text { Courneya et al. } \\
2003 \text { [40] }\end{array}$ & Y & N & Y & $\mathrm{N}$ & $\mathrm{N}$ & Y & Y & Y & Y & Y & 7 \\
\hline $\begin{array}{l}\text { Ergun et al. } \\
2013 \text { [41] }\end{array}$ & Y & $\mathrm{N}$ & Y & $\mathrm{N}$ & N & Y & Y & $N$ & Y & Y & 6 \\
\hline $\begin{array}{l}\text { Milne et al. } \\
2008 \text { [42] }\end{array}$ & Y & Y & Y & $\mathrm{N}$ & N & $\mathrm{N}$ & Y & Y & Y & Y & 7 \\
\hline $\begin{array}{l}\text { Mutrie et al. } \\
2007 \text { [43] }\end{array}$ & Y & $Y$ & $Y$ & $\mathrm{~N}$ & N & Y & $Y$ & $Y$ & Y & Y & 8 \\
\hline $\begin{array}{l}\text { Saarto et al. } \\
2012[44]\end{array}$ & Y & $\mathrm{N}$ & Y & $\mathrm{N}$ & N & $\mathrm{N}$ & Y & $N$ & Y & Y & 5 \\
\hline $\begin{array}{l}\text { Segal et al. } \\
2001[45]\end{array}$ & Y & $\mathrm{N}$ & Y & $\mathrm{N}$ & N & $\mathrm{N}$ & $\mathrm{N}$ & Y & Y & Y & 5 \\
\hline $\begin{array}{l}\text { Winters et al. } \\
2012 \text { [46] }\end{array}$ & Y & Y & Y & $\mathrm{N}$ & $N$ & Y & $N$ & Y & Y & Y & 7 \\
\hline
\end{tabular}




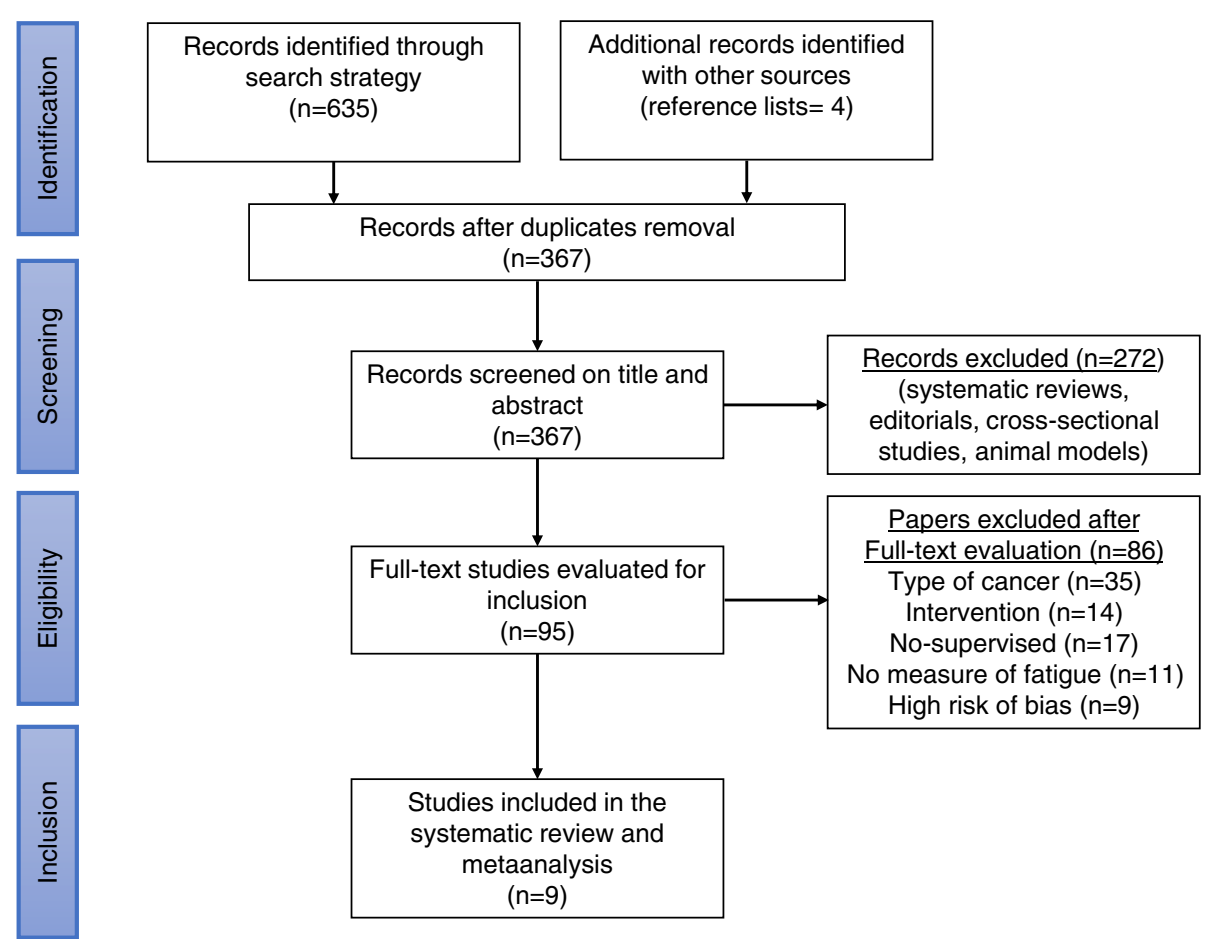

Figure 1 Flowdiagram for search strategy methods. Flowdiagram is performed according to PRISMA Statement.

(SD 0.7) sessions per week. Training intensity varied substantially among studies, ranging from $50 \%$ to $80 \%$ maximal heart rate (Table 2).

\section{Adverse effects}

No major adverse effects were reported among studies. Courneya et al. [40] reported five adverse events in the exercise group (lymphedema, gynecologic complaints and influenza), while two adverse events (foot fracture and bronchitis) occurred in the control group. Cantarero et al. [39] reported discomfort or low-intensity pain/stiffness after an exercise session in 3 patients; however, these patients completed the exercise program. Conversely, Ergun et al. [41] and Winster et al. [46] reported no adverse effects, including lymphedema, with exercise interventions.

\section{Pooled effects estimates for outcome measures Cancer-related fatigue (CRF)}

Pooled analysis demonstrated that supervised aerobic exercise was statistically more effective than conventional care in improving CRF among breast cancer survivors $(\mathrm{SMD}=-0.51,95 \% \mathrm{CI}-0.81$ to -0.21$)$, with high statistical heterogeneity $\left(P=0.001 ; \mathrm{I}^{2}=75 \%\right)$ (Figure 2$)$. Regarding subgroup analysis, the pooled SMD for supervised resistance training was -0.41 ( $95 \% \mathrm{CI}-0.76$ to -0.05$)$, indicating a moderate reduction in fatigue from this mode of training (Figure 3). The effect of stretching exercise on CRF levels was addressed by only one study [42], preventing the calculation of pooled effect estimates for this mode of training.

\section{Meta-regression: heterogeneity and dose-response interaction}

Our meta-regression analysis showed that publication year $(P<0.0001)$ and the length $(P=0.02)$ (Figure 4$)$, duration $(P<0.0001)$, and frequency $(P<0.0001)$ of the supervised exercise interventions were significantly associated with reductions on fatigue levels. No significant dose-response interaction was observed for training intensity $(P>0.05)$.

\section{Publication bias}

Moderate evidence of publication bias was detected for the effects of supervised exercise interventions on CRF by the Egger's test $(P=0.04)$.

\section{Effects of supervised exercise on CRF based on cancer treatment stage}

Five studies $[38,40,42,43,45]$ evaluated the effects of supervised exercise on CRF in breast cancer receiving active anti-cancer treatment (i.e., chemotherapy, radiotherapy, hormone therapy or combination). The subgroup analysis showed significant benefits from supervised exercise during active treatment $(\mathrm{SMD}=-0.66,95 \% \mathrm{CI}-1.08$ to -0.23$)$, high statistical heterogeneity was detected $\left(P=0.002 ; \mathrm{I}^{2}=\right.$ 
Table 2 Characteristics of the studies included

\begin{tabular}{|c|c|c|c|c|c|}
\hline Study & Design & $\begin{array}{l}\text { Breast } \\
\text { cancer } \\
\text { description }\end{array}$ & Participants* & Intervention** & Outcome measures \\
\hline \multirow[t]{6}{*}{$\begin{array}{l}\text { Campbell et al. } \\
2005 \text { [38] }\end{array}$} & \multirow[t]{6}{*}{$\mathrm{RCT}$} & \multirow[t]{6}{*}{$\begin{array}{l}\text { Early stage } \\
(\text { (I-I) Breast } \\
\text { cancer }\end{array}$} & $\begin{array}{l}\text { Characteristics of cancer treatment }= \\
\text { Chemotherapy, radiotherapy and } \\
\text { combination. }\end{array}$ & $\begin{array}{l}\text { Exp }=\text { Aerobic exercise and resistance } \\
\text { training }\end{array}$ & \multirow[t]{6}{*}{$\begin{array}{l}\text { FACT-G, FACT-B, SWLS, } \\
\text { PFS, SPAQ, 12-minute } \\
\text { walk test }\end{array}$} \\
\hline & & & $N=22$ & Length = 12 weeks. & \\
\hline & & & Female $=22$ & Duration $=20 \mathrm{~min} / \mathrm{session}$ & \\
\hline & & & $\operatorname{Exp}(n=12)$ & Frequency = 2 session/week & \\
\hline & & & Age $(y r)=48(10)$ & Intensity $=60 \%-75 \%$ & \\
\hline & & & Age $(y r)=47(5)$ & Con $=$ Conventional care & \\
\hline \multirow[t]{8}{*}{$\begin{array}{l}\text { Cantarero et al. } \\
2013 \text { [39] }\end{array}$} & \multirow[t]{8}{*}{$\mathrm{RCT}$} & \multirow[t]{8}{*}{$\begin{array}{l}\text { Breast cancer } \\
\text { (stages I-IIIA) }\end{array}$} & $\begin{array}{l}\text { Characteristics of cancer treatment }= \\
\text { Chemotherapy radiotherapy and } \\
\text { combination. }\end{array}$ & $\begin{array}{l}\text { Exp }=\text { Aerobic exercise and resistance } \\
\text { training }\end{array}$ & \multirow[t]{2}{*}{$\begin{array}{l}\text { PFS, The Spanish version } \\
\text { of the Profile of }\end{array}$} \\
\hline & & & & Length $=8$ weeks & \\
\hline & & & $N=61$ & Duration $=60 \mathrm{~min} /$ session & \multirow{6}{*}{$\begin{array}{l}\text { Mood States, The } \\
\text { "multiple sit-to-stand } \\
\text { test", The trunk curl } \\
\text { static endurance test }\end{array}$} \\
\hline & & & Female $=61$ & Frequency = 3 session/week & \\
\hline & & & $\operatorname{Exp}(n=32)$ & Intensity = 60\%-75\% & \\
\hline & & & Age $(y r)=49(7)$ & Con $=$ Conventional care & \\
\hline & & & Con $(n=29)$ & & \\
\hline & & & Age $(y r)=47(8)$ & & \\
\hline \multirow[t]{7}{*}{$\begin{array}{l}\text { Courneya et al. } \\
2003[40]\end{array}$} & \multirow[t]{7}{*}{ RCT } & \multirow{7}{*}{$\begin{array}{l}\text { Early stage } \\
\text { Breast cancer }\end{array}$} & $\begin{array}{l}\text { Characteristics of cancer treatment }= \\
\text { Chemotherapy }- \text { Radiotherapy }\end{array}$ & Exp $=$ Aerobic exercise & \multirow[t]{7}{*}{ FACT- G, FACT-B, FACT-F } \\
\hline & & & $N=52$ & Length $=15$ weeks & \\
\hline & & & Female $=52$ & Duration $=35 \mathrm{~min} /$ session & \\
\hline & & & $\operatorname{Exp}(n=24)$ & Frequency $=3$ session/week & \\
\hline & & & Age $(y r)=59(5)$ & Intensity $=70 \%-75 \%$ & \\
\hline & & & Con $(n=28)$ & Con $=$ Conventional care & \\
\hline & & & Age $(y r)=58(6)$ & & \\
\hline \multirow[t]{9}{*}{$\begin{array}{l}\text { Ergun et al. } \\
2013 \text { [41] }\end{array}$} & \multirow[t]{9}{*}{ RCT } & \multirow[t]{9}{*}{$\begin{array}{l}\text { Breast cancer } \\
\text { (stages I-IIIA) }\end{array}$} & $\begin{array}{l}\text { Characteristics of cancer treatment = } \\
\text { Chemotherapy, radiotherapy, } \\
\text { mastectomy, axillary dissection and } \\
\text { sentinel lymph node biopsy }\end{array}$ & $\begin{array}{l}\text { Exp }=\text { Aerobic exercise and resistance } \\
\text { training. }\end{array}$ & \multirow[t]{2}{*}{$\begin{array}{l}\text { EORTC QLQ-C30, BFI, } \\
\text { BDI, ELISA kit, RayBio } \\
\text { Human }\end{array}$} \\
\hline & & & $N=60$ & Length $=12$ weeks & \\
\hline & & & Female $=60$ & Duration $=45 \mathrm{~min} / \mathrm{session}$ & \multirow{7}{*}{$\begin{array}{l}\text { Cytokine Antibody } \\
\text { Array } 3\end{array}$} \\
\hline & & & $\operatorname{Exp}(n=20)$ & Frequency $=3$ session/week & \\
\hline & & & Age $(y r)=49.65(8.25)$ & Intensity = 60\%-80\% & \\
\hline & & & Home-based exercise $(n=20)$ & $\begin{array}{l}\text { Con }=\text { Home-based exercise (brisk } \\
\text { walking for } 30 \mathrm{~min} / \text { day for } 3 \text { days/ } \\
\text { week) + education programme }\end{array}$ & \\
\hline & & & Age $(y r)=55.05(6.85)$ & $\begin{array}{l}\text { Education group = patient } \\
\text { information booklet that also } \\
\text { included lymphedema-specific } \\
\text { exercises }\end{array}$ & \\
\hline & & & Education group $(n=20)$ & & \\
\hline & & & Age $(y r)=55.30(10.37)$ & & \\
\hline \multirow[t]{4}{*}{$\begin{array}{l}\text { Milne et al. } \\
2008 \text { [42] }\end{array}$} & \multirow[t]{4}{*}{$\mathrm{RCT}$} & \multirow[t]{4}{*}{$\begin{array}{l}\text { Early stage } \\
\text { Breast cancer }\end{array}$} & $\begin{array}{l}\text { Characteristics of cancer treatment }= \\
\text { Chemotherapy - Radiotherapy }\end{array}$ & $\begin{array}{l}\text { Exp }=\text { Aerobic exercise, resistance } \\
\text { training and stretching. }\end{array}$ & \multirow[t]{4}{*}{$\begin{array}{l}\text { FACT-B, SCFS, rPARQ, } \\
\text { Aerobic Power Index }\end{array}$} \\
\hline & & & $N=58$ & Length = 12 weeks. & \\
\hline & & & Female $=58$ & Duration $=30 \mathrm{~min} / \mathrm{ses}$ & \\
\hline & & & $\operatorname{Exp}(n=29)$ & Frequency $=3$ ses $/$ wk. & \\
\hline
\end{tabular}


Table 2 Characteristics of the studies included (Continued)

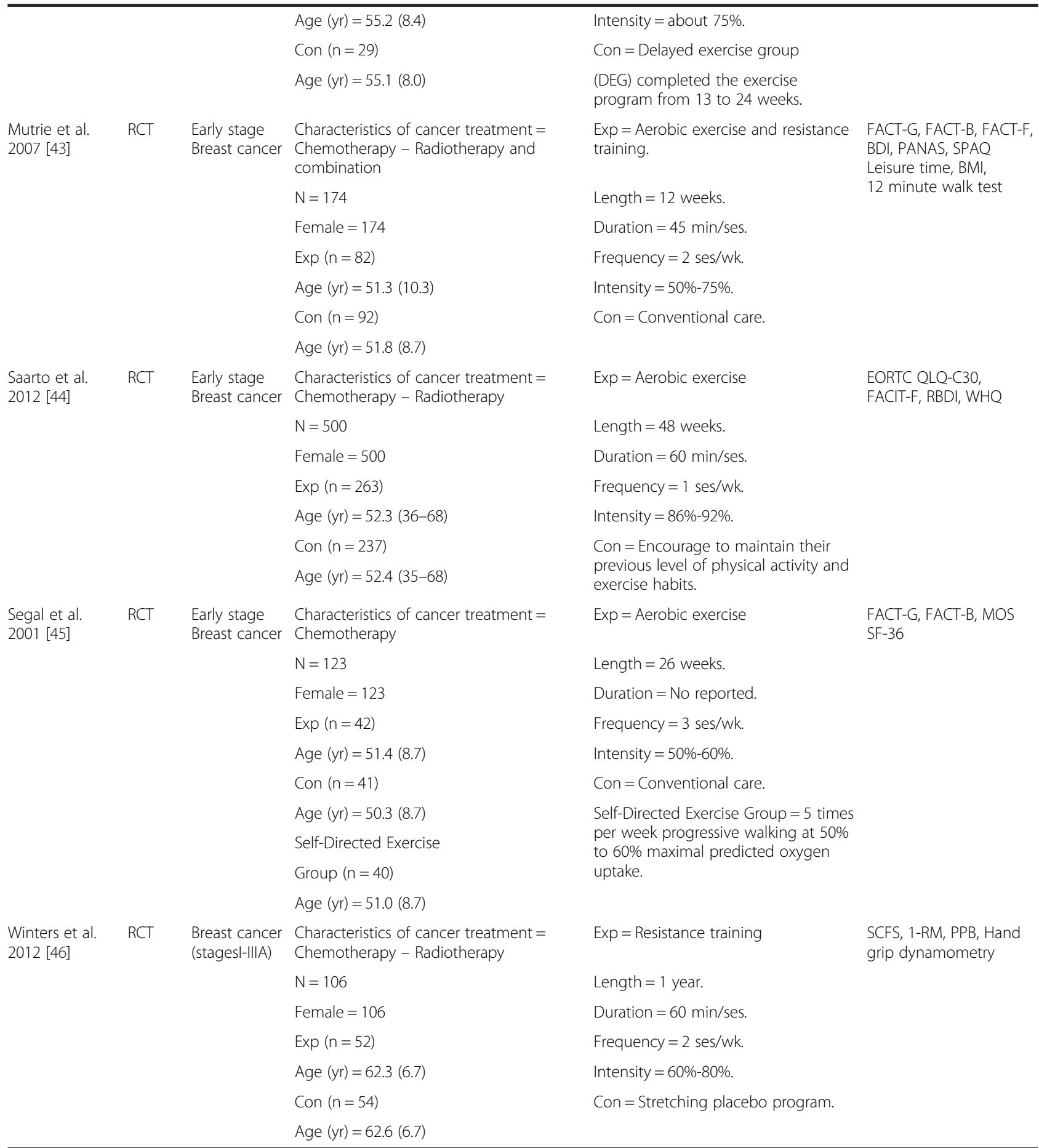

Beck Depression Inventory, BDI; The Brief Fatigue Inventory, BFI; DXA (Dual-energy X-ray Absorptiometry); European Organization for Research and Treatment of Cancer Quality of Life Questionnaire, EORTC QLQ-C30; Finnish modified version of Beck's 13-item depression scale, RBDI; Functional Assessment of Cancer Therapy, FACT - Breast (FACT-B), Fatigue (FACT-F), General (FACT-G); Functional Assessment of Chronic Illness Therapy (FACIT) questionnaire for fatigue (FACIT-F); Medical Outcomes Study Short Form, MOS SF-36; Multidimensional Fatigue Inventory, MFSI-SF; Physical Activity Readiness Questionnaire, PARQ; Physical Performance Battery, PPB; Piper Fatigue Scale, PFS; Positive And Negative Affect Scale, PANAS; Scottish Physical Activity Questionnaire, SPAQ; Schwartz Cancer Fatigue Scale, SCFS; Satisfaction with Life Scale, SWLS; Women's Health Questionnaire, WHQ.

*Age presented with mean and SD or range where reported.

**Supervised physical activity interventions usually consisted of a warm-up period, aerobic training (walking, cycling-ergometers and circuits), muscle strength training (chest and leg curls), stretching exercises and a cool-down and relaxation period. 


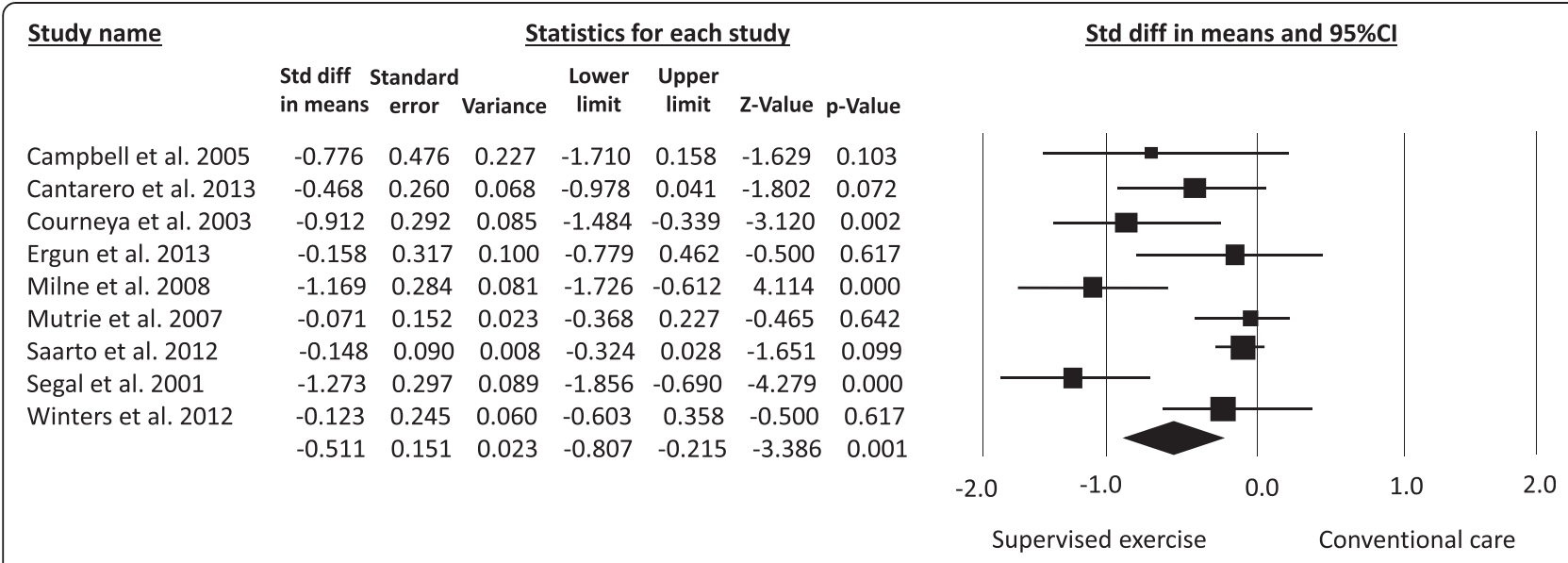

Figure 2 Metaanalysis for the effect estimate of supervised exercise on CRF in Breast cancer survivors. Standardized mean difference (SMD) was calculated for the Random effects model of metaanalysis. IV, inverse of variance; Cl, confidence interval.

83.6\%). Four studies implemented supervised exercise in breast cancer survivors after anti-cancer treatment $[39,41,44,46]$. The pooled effect was not statistically $(\mathrm{SMD}=-0.25,95 \% \mathrm{CI}-0.55$ to 0.05$)$ with high statistical heterogeneity $\left(P=0.10 ; \mathrm{I}^{2}=76 \%\right)$ (Figure 5$)$. Time since diagnosis was not consistently reported by authors, although most of the studies recruited women who were beyond five years since primary cancer diagnosis. Hormone therapy included Tamoxifen and aromatase inhibitors. See Table 3 for further details.

\section{Results for secondary outcome measures}

As shown in Table 3, supervised exercise interventions significantly improved functional and physical wellbeing, but no significant effects were observed for social and emotional well-being domains. There were no significant differences between the supervised exercise group and the control group in depression, BMI and physical activity level $(P>0.05)$.

\section{Discussion}

Our meta-analysis revealed that supervised exercise has a favorable effect on cancer-related fatigue when compared with conventional care and it can be considered as a safe therapy for the management of fatigue and other domains of quality of life in breast cancer survivors. These findings are in accordance with those recently reported by Velthuis et al. [20] and Cramp et al. [17], who found that exercise improved the psychosocial and physical outcomes in cancer survivors during and after treatment. Buffart et al. [47] recently stated that it is necessary to continue studying the guidelines for exercise prescription for cancer patients, specifically regarding the type, localization and side effects related to treatment.

In our subgroup analysis, resistance training significantly improved CRF (SMD $=-0.55 ; 95 \% \mathrm{CI},-1.09$ to -0.01$)$. Similar results have been published in the literature. Milne et al. [42] reported that resistance training produced important benefits on CRF and muscular strength in breast

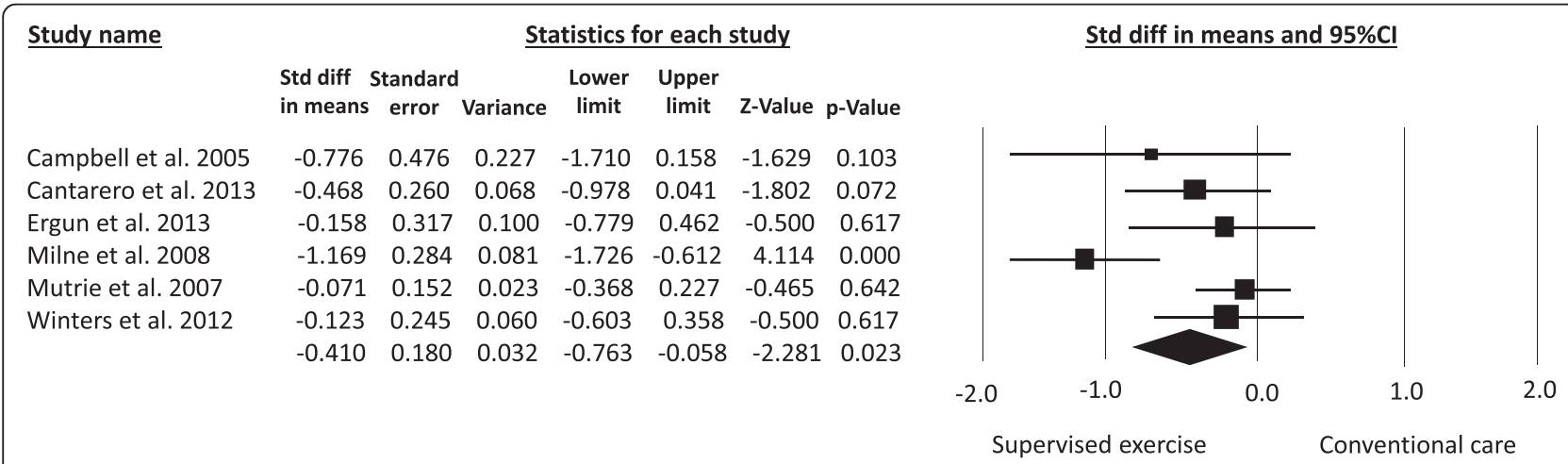

Figure 3 Metaanalysis for the effect estimate of supervised resistance training on CRF in Breast cancer survivors. Standardized mean difference was (SMD) calculated for the Random effects model of metaanalysis. IV, inverse of variance; Cl, confidence interval. 


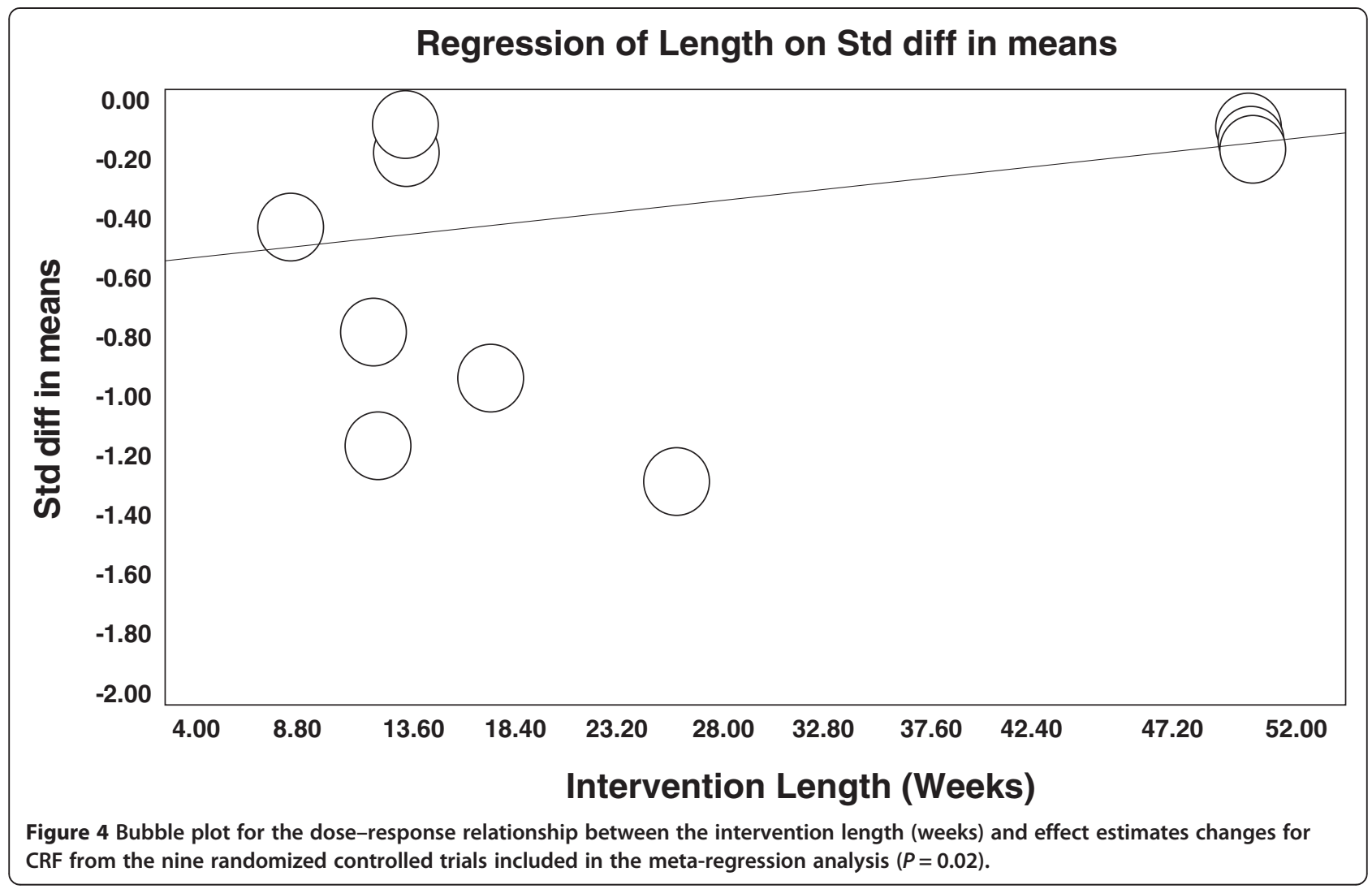

cancer survivors after adjuvant therapy. Similar findings were confirmed by Yuen and Sword in 2007 [48]. In a recent meta-analysis, Strasser et al. [49] found that resistance training during active treatment produced important gains in muscular strength and body composition. Muscular strength was not evaluated in our study due to the large differences in the reports obtained from the studies included. Only one study examined the effects of stretching exercise programs and found it to be beneficial [42].

It has been reported that supervision plays an important role in the benefits of exercise among breast cancer survivors [20]. The mechanism underlying the benefit of

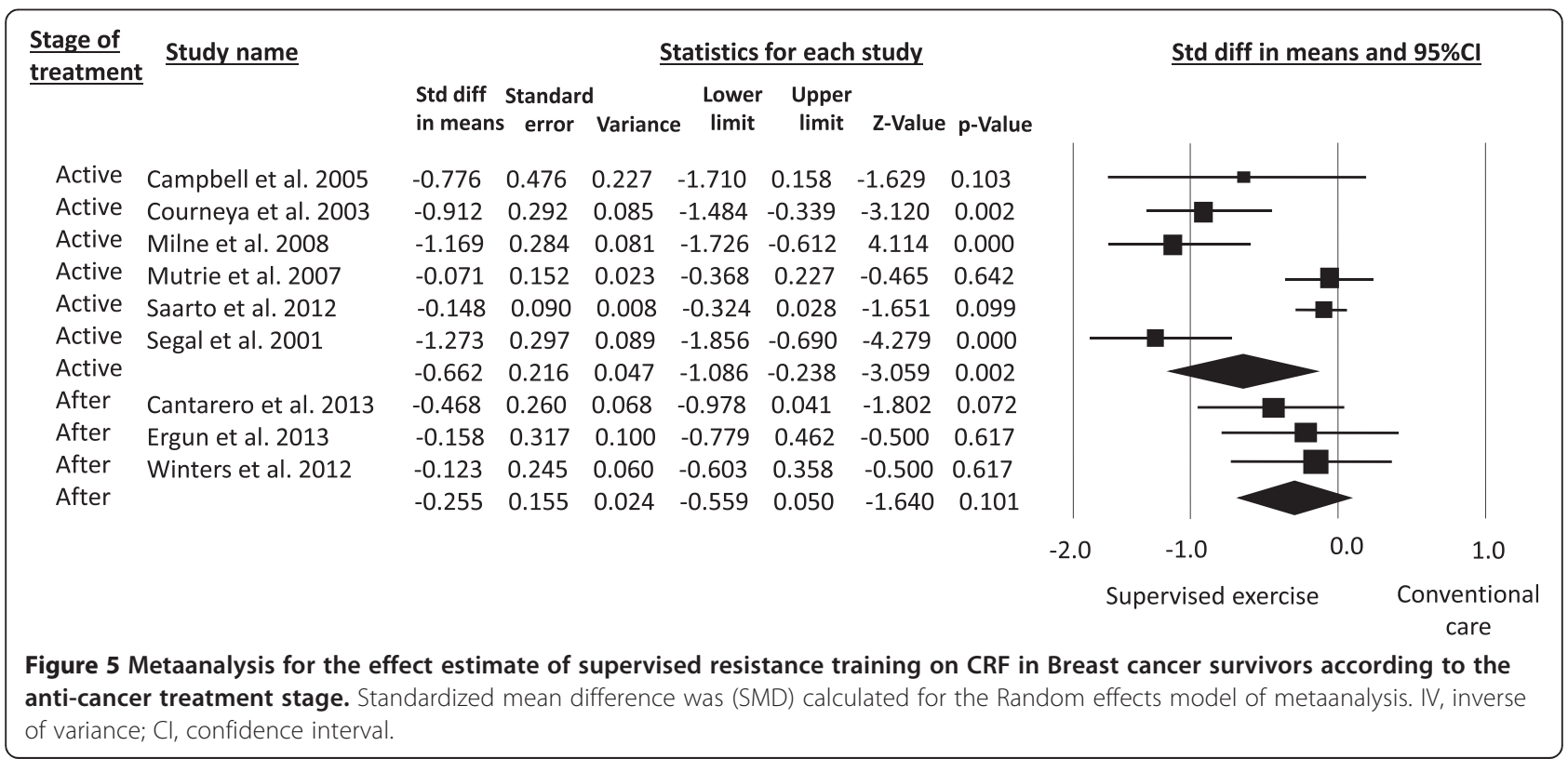


Table 3 Effect size estimates for comparisons and secondary outcomes included in the meta-analysis

\begin{tabular}{|c|c|c|}
\hline Outcome & Effect size random effects model $-\mathrm{SMD}^{*}(95 \% \mathrm{Cl})$ & Statistical heterogeneity $\left(\mathrm{I}^{2}\right)$ \\
\hline \multicolumn{3}{|l|}{ Primary outcome (CRF) } \\
\hline Supervised aerobic exercise & $-0.51,95 \% \mathrm{Cl}[-0.81,-021],(P=0.001) \dagger$ & $75 \%$ \\
\hline Supervised resistance training & $-0.41,95 \% \mathrm{Cl}[-0.76,-0.05],(P=0.02) \dagger$ & $64 \%$ \\
\hline Supervised exercise during active anti-cancer treatment & $-0.66,95 \% \mathrm{Cl}[-1.08,-0.23],(\mathrm{P}=0.002) \dagger$ & $78.6 \%$ \\
\hline Supervised exercise after anti-cancer treatment & $-0.25,95 \% \mathrm{Cl}[-0.55,0.05],(P=0.10)$ & $85.8 \%$ \\
\hline \multicolumn{3}{|l|}{ Secondary outcomes } \\
\hline Depression & $-0.23,95 \% \mathrm{Cl}[-0.55,0.09],(P=0.16)$ & $69 \%$ \\
\hline Body mass index & $-0.14,95 \% \mathrm{Cl}[-0.38,0.11],(P=0.28)$ & $0 \%$ \\
\hline Physical activity level & $1.10,95 \% \mathrm{Cl}[-0.41,2.62],(\mathrm{P}=0.15)$ & $85 \%$ \\
\hline \multicolumn{3}{|l|}{ Health-related quality of life } \\
\hline Physical wellbeing & $0.63,95 \% \mathrm{Cl}[0.08,1.18],(P=0.02) \dagger$ & $89 \%$ \\
\hline Functional wellbeing & $0.60,95 \% \mathrm{Cl}[0.08,1.11],(P=0.02) \dagger$ & $89 \%$ \\
\hline Social wellbeing & $0.08,95 \% \mathrm{Cl}[-0.11,0.27],(P=0.24)$ & $28 \%$ \\
\hline Emotional wellbeing & $0.30,95 \% \mathrm{Cl}[-0.05,0.65],(P=0.09)$ & $76 \%$ \\
\hline
\end{tabular}

*Standarized mean difference.

† Significant differences observed $(P<0.05)$

Cancer-related fatigue, CRF.

supervision could be attributed to improvements in adherence and intensity, perhaps because of greater encouragement or confidence when the help of a health professional is available. In 2009, Whitehead and Lavelle [50] reported that breast cancer survivors preferred supervised exercise training compared to unsupervised exercise. Recently, Markes et al. [51] compared supervised and non-supervised exercise in breast cancer survivors and reported nonsignificant differences between groups, although the authors reported significant improvements in fitness and daily activities. In light of this, our results demonstrate a favorable tendency in favor of supervised interventions, although our recommendations need to be confirmed by larger randomized controlled trials.

When examining statistical heterogeneity, we found significant positive impacts on CRF with increasing length, duration and frequency of the supervised exercise interventions. Meta-regression analysis showed than exercise interventions performed for more than 28 weeks, nearly 3 sessions per week and lasting 40 minutes per session exert larger effects that low-volume exercise interventions. These dose-response relationships are in agreement with two recent meta-analyses published by Brown et al. [11] and Strasser et al. [14]. On the contrary, we observed no statistically significant dose-response relationship between high intensity ( $>80 \%$ maximal heart rate) of supervised exercise and CRF in breast cancer survivors, even though a strong body of research from previous meta-analyses have demonstrated that high-intensity aerobic and resistance training can provide larger effects than aerobic exercise alone on CRF $[11,14,17,20]$. Hence, further research is needed to elucidate the role of supervised exercise intensity and the optimal dose of exercise in the management of CRF in women with breast cancer.

An additional relevant finding related to this metaanalysis is that we observed significant benefits on several domains of quality of life (physical and functional well-being) in breast cancer survivors following supervised exercise (see Table 3 ). These results are consistent with those recently reported by Mishra et al. [52] in a recent Cochrane review concerning exercise and quality of life in cancer survivors. The authors concluded that exercise improves some health-related quality of life domains, such as functional well-being, cancer-specific concerns (e.g., breast cancer), anxiety, fatigue, and other outcomes. Interestingly, the authors encouraged further research to investigate the effects of different training modalities. On the other hand, no evidence of any effect was observed for depression $(P=0.16)$, body mass index $(P=0.28)$ and physical activity level $(P=0.15)$. This lack of significance could be explained by the small number of studies that reported effect estimates for these outcomes and the evident clinical heterogeneity in their measurement. Conversely, other studies have reported consistent changes in depression after exercise interventions in cancer survivors [53].

Our study has several limitations. Emerging evidence has suggested that physical exercise can improve systemic inflammation in cancer survivors [54-57], and it is widely known that cytokines and inflammatory markers are associated with CRF levels [58], though not all studies agree [59-61]. Additionally, it was not possible to evaluate the changes on inflammatory markers following supervised exercise, since only Ergun et al. [41] reported 
data of the inflammatory markers; therefore, further trials are required to achieve consensus on this topic. The statistical heterogeneity of our results can be attributed to the variability in reporting of several outcome measures (i.e., fatigue, depression, data for quality of life, etc.), intervention procedures and tools used. This reporting heterogeneity and the low availability of data from the studies prevented the analysis of other outcomes, such as muscular strength, and blood biomarkers, including inflammatory cytokines, leptin, glucose-related markers and other tumoral markers. The observed heterogeneity in reporting procedures leads us to recommend that further clinical trials be conducted in a more uniform way in order to achieve strong consensus about the effects of exercise training for breast cancer survivors.

\section{Conclusions}

In summary, our findings demonstrate that supervised exercise could be considered a safe and effective intervention in improving cancer-related fatigue among breast cancer survivors. On the basis of our results, we recommend that supervised and structured exercise programs be prescribed to breast cancer survivors, regardless of treatment stage as a means to improve cancer-related fatigue and some domains of overall quality of life. Further research is required to strengthen this evidence.

\section{Annexes}

\section{Appendix 1. Search strategy details}

1. randomized controlled trial [Publication Type]

2. controlled clinical trial [Publication Type]

3. randomi"ed [Title/Abstract]

4. trial [Title]

5. "clinical trials as topic" [MeSH Major Topic]

6. \#1 OR \#2 OR \#3 OR \#4 OR \#5

7. Breast cancer [Title/Abstract]

8. (tumour* or tumor*) [Title/Abstract]

9. carcino* [Title/Abstract]

10.\#7 OR \#8 OR \#9

11.Exercise [Title/Abstract]

12.Physical activity [Title/Abstract]

13.Aerobic [Title/Abstract]

14.Resistance [Title/Abstract]

15.Strength [Title/Abstract]

16.Flexibility [Title/Abstract]

17.Stretching [Title/Abstract]

18.\#13 OR \#14 OR \#15 OR \#16 OR \#17

19.fatigue [Title/Abstract]

20.Cancer-related fatigue [Title/Abstract]

21.\#19 OR \#20

31.\#6 AND \#10 AND \#18 AND \#21

\section{Competing interests}

The authors declare that they have no competing interests.

\section{Authors' contributions}

Study Concept and design: JFM-E, RR-V; Search Strategy: JFM-E, RR-V; Ethic proclamations: JFME-E; Selection Criteria: JFM-E and EG-J; Data Extraction: JFM-E and RR-V; Quality Assessment: JFM-E, EG-J and RR-V; Drafting of the Manuscript: JFM-E, EG-J and RR-V. All authors read and approved the final manuscript.

\section{Authors' information}

JFM-E and RR-V are associate professors and researchers in the Research Group GICAEDS of the Facultad de Cultura Física, Deporte y Recreación, Universidad Santo Tomás. Bogotá, Colombia. EGJ is assistant professor in the Departamento de Enfermería, Universidad de Granada. España

\section{Acknowledgements}

The authors would like to acknowledge Universidad Santo Tomás, Bogotá for the financial support to the GICAEDS Group (Project: Práctica del autoexamen de seno y los conocimientos, factores de riesgo y estilos de vida relacionados al cáncer de mama en mujeres jóvenes de la USTA Number: 4110060001-008). The authors wish to thank Michael Garber for the correction of the English style.

\section{Author details}

${ }^{1}$ Grupo GICAEDS. Facultad de Cultura Física, Deporte y Recreación, Universidad Santo Tomás, Bogotá, D.C, Colombia. ${ }^{2}$ Departamento de Enfermería. Facultad de Ciencias de la Salud, Universidad de Granada, Granada, Spain.

Received: 31 May 2014 Accepted: 3 February 2015

Published online: 21 February 2015

\section{References}

1. American Cancer Society. Cancer facts \& figures 2012 [http://www.cancer. org/Research/CancerFactsFigures/index]

2. American Cancer Society. Cancer facts \& figures for Hispanics/Latinos 2009- 2011 [http://www.cancer.org/research/CancerFactsFigures/ CancerFactsFiguresforHispanicsLatinos/index]

3. Jemal A, Bray F, Center MM, Ferlay J, Ward E, Forman D. Global cancer statistics. CA Cancer J Clin. 2011;61(2):69-90.

4. Luciani S, Cabanes A, Prieto-Lara E, Gawryszewski V. Cervical and female breast cancers in the Americas: current situation and opportunities for action. Bull World Health Organ. 2013;91(9):640-9.

5. Piñeros M, Gamboa O, Hernández-Suárez G, Pardo C, Bray F. Patterns and trends in cancer mortality in Colombia 1984-2008. Cancer Epidemiol. 2013;37(3):233-9.

6. Jemal A, Center MM, DeSantis C, Ward E. Global patterns of cancer incidence and mortality rates and trends. Cancer Epidemiol Biomarkers Prev. 2010;19:1893-907.

7. Siegel R, Naishadham D, Jemal A. Cancer statistics. CA Cancer J Clin. 2012;62(1):10-29.

8. Mortimer JE, Barsevick AM, Bennett CL, Berger AM, Cleeland C, DeVader SR, et al. Studying cancer-related fatigue: report of the NCCN scientific research committee. J Natl Compr Canc Netw. 2010;8(12):1331-9.

9. Stone P, Richardson A, Ream E, Smith AG, Kerr DJ, Kearney N. Cancer related fatigue, inevitable, unimportant and untreatable? results of a multi-centre patient survey. Cancer fatigue forum. Ann Oncol. 2000;11:971-5.

10. Groenvold M, Petersen MA, Idler E, Bjorner JB, Fayers PM, Mouridsen HT. Psychological distress and fatigue predicted recurrence and survival in primary breast cancer patients. Breast Cancer Res Treat. 2007;105:209-19.

11. Brown JC, Huedo-Medina TB, Pescatello LS, Pescatello SM, Ferrer RA, Johnson BT. Efficacy of exercise interventions in modulating cancer-related fatigue among adult cancer survivors: a meta-analysis. Cancer Epidemiol Biomarkers Prev. 2011;20:123-33.

12. Mishra SI, Scherer RW, Geigle PM, Berlanstein DR, Topaloglu O, Gotay CC, et al. Exercise interventions on health-related quality of life for cancer survivors. Cochrane Database Syst Rev. 2012;8:CD007566.

13. Szymlek-Gay EA, Richards R, Egan R. Physical activity among cancer survivors: a literature review. N Z Med J. 2011;124(1337):77-89. 
14. Meneses-Echávez JF, González-Jiménez E, Ramírez-Vélez R. Supervised exercise reduces cancer-related fatigue: a systematic review. J Physiother 2015;61(1):3-9

15. Rajarajeswaran P, Vishnupriya R. Exercise in cancer. Indian J Med Paediatr Oncol. 2009;30:61-70.

16. Carayol M, Bernard P, Boiché J, Riou F, Mercier B, Cousson-Gélie F, et al. Psychological effect of exercise in women with breast cancer receiving adjuvant therapy: what is the optimal dose needed? Ann Oncol. 2013;24:291-300.

17. Cramp F, Byron-Daniel J. Exercise for the management of cancer-related fatigue in adults. Cochrane Database Syst Rev. 2012;11:CD006145.

18. Loprinzi PD, Cardinal BJ. Effects of physical activity on common side effects of breast cancer treatment. Breast Cancer. 2012;19(1):4-10.

19. Speck RM, Courneya KS, Mâsse LC, Duval S, Schmitz KH. An update of controlled physical activity trials in cancer survivors: a systematic review and meta-analysis. J Cancer Surviv. 2010:4(2):87-100.

20. Velthuis MJ, Agasi-Idenburg SC, Aufdemkampe G, Wittink HM. The effect of physical exercise on cancer-related fatigue during cancer treatment: a meta-analysis of randomised controlled trials. Clin Oncol (R Coll Radiol). 2010;22(3):208-21.

21. Wanchai A, Armer JM, Stewart BR. Non pharmacologic supportive strategies to promote quality of life in patients experiencing cancer-related fatigue: a systematic review. Clin J Oncol Nurs. 2011;15(2):203-14.

22. Kangas M, Bovbjerg DH, Montgomery GH. Cancer-related fatigue: a systematic and meta-analytic review of non-pharmacological therapies for cancer patients. Psychol Bull. 2008;134(5):700-41.

23. Jacobsen PB, Donovan KA, Vadaparampil ST, Small BJ. Systematic review and meta-analysis of psychological and activity-based interventions for cancer-related fatigue. Health Psychol. 2007;26(6):660-7.

24. Chang CW, Mu PF, Jou ST, Wong $\Pi$, Chen YC. Systematic review and meta-analysis of non-pharmacological interventions for fatigue in children and adolescents with cancer. World Views Evid Based Nurs. 2013;10(4):208-17.

25. Oechsle K, Aslan Z, Suesse Y, Jensen W, Bokemeyer C, de Wit M. Multimodal exercise training during myeloablative chemotherapy: a prospective randomized pilot trial. Support Care Cancer. 2014:22:63-9.

26. Schneider CM, Hsieh CC, Sprod LK, Carter SD, Hayward R. Effects of supervised exercise training on cardiopulmonary function and fatigue in breast cancer survivors during and after treatment. Cancer. 2007;110(4):918-25.

27. Cho MH, Dodd MJ, Cooper BA, Miaskowski C. Comparisons of exercise dose and symptom severity between exercisers and non exercisers in women during and after cancer treatment. J Pain Symptom Manage. 2012;43 (5):842-54.

28. Zopf EM, Baumann FT, Pfeifer K. Physical activity and exercise recommendations for cancer patients during rehabilitation. Rehabilitation (Stuttg). 2014:53(1):2-7.

29. Moher D, Liberati A, Tetzlaff J, Altman DG, The PRISMA Group. Preferred reporting items for systematic reviews and meta-analyses: The PRISMA statement. PLoS Med. 2009;6:e1000097.

30. Robinson KA, Dickersin K. Development of a highly sensitive search strategy for the retrieval of reports of controlled trials using PubMed. Int J Epidemiol. 2002:31(1):150-3.

31. Wolin KY, Schwartz AL, Matthews CE, Courneya KS, Schmitz KH. Implementing the exercise guidelines for cancer survivors. J Support Oncol. 2012;10:171-7.

32. Verhagen AP, de Vet HC, de Bie RA, Kessels AG, Boers M, Bouter LM, et al. The Delphi list: a criteria list for quality assessment of randomised clinical trials for conducting systematic reviews developed by Delphi consensus. J Clin Epidemiol. 1998;51(12):1235-41.

33. Moseley AM, Herbert RD, Sherrington C, Maher CG. Evidence for physiotherapy practice: a survey of the physiotherapy evidence database (PEDro). Aust J Physiother. 2002;48(1):43-9.

34. National Comprehensive Cancer Network. Clinical Practice Guidelines in Oncology (2014) [http://www.nccn.org/professionals/physician_gls/ f_guidelines.asp\#fatigue]

35. Review Manager (RevMan). [Computer program]. Version 5.1. Copenhagen: The Nordic Cochrane Centre, The Cochrane Collaboration; 2014.

36. Higgins JPT, Green S (editors). Cochrane Handbook for Systematic Reviews of Interventions Version 5.1.0 [updated March 2011]. The Cochrane Collaboration, 2011. Available from www.cochrane-handbook.org.
37. Higgins JP, Thompson SG, Deeks JJ, Altman DG. Measuring inconsistency in meta-analyses. BMJ. 2003;327(7414):557-60.

38. Campbell A, Mutrie N, White F, McGuire F, Kearney N. A pilot study of a supervised group exercise programme as a rehabilitation treatment for women with breast cancer receiving adjuvant treatment. Eur J Oncol Nurs. 2005;9(1):56-63.

39. Cantarero-Villanueva I, Fernández-Lao C, Cuesta-Vargas Al, Del Moral-Avila R, Fernández-de-Las-Peñas C, Arroyo-Morales M. The effectiveness of a deep water aquatic exercise program in cancer-related fatigue in breast cancer survivors: a randomized controlled trial. Arch Phys Med Rehabil. 2013;94(2):221-30

40. Courneya KS, Mackey JR, Bell GJ, Jones LW, Field CJ, Fairey AS. Randomized controlled trial of exercise training in postmenopausal breast cancer patients: cardiopulmonary and quality of life outcomes. J Clin Oncol. 2003:21:1660-8

41. Ergun M, Eyigor S, Karaca B, Kisim A, Uslu R. Effects of exercise on angiogenesis and apoptosis-related molecules, quality of life, fatigue and depression in breast cancer patients. Eur J Cancer Care (Engl). 2013;22(5):626-37.

42. Milne HM, Wallmanke, Gordon S, Courneya KS. Effects of a combined aerobic and resistance exercise program in breast cancer survivors: a randomized controlled trial. Breast Cancer Res Treat. 2008;108:279-88.

43. Mutrie N, Campbell AM, Whyte F, McConnachie A, Emslie C, Lee L, et al. Benefits of supervised group exercise programme for women being treated for early stage breast cancer, pragmatic randomised controlled trial. BMJ. 2007;334(7592):517.

44. Saarto T, Penttinen HM, Sievänen H, Kellokumpu-Lehtinen PL, HakamiesBlomqvist L, Nikander R, et al. Effectiveness of a 12-month exercise program on physical performance and quality of life of breast cancer survivors. Anticancer Res. 2012;32(9):3875-84.

45. Segal R, Evans W, Johnson D, Smith J, Colletta S, Gayton J, et al. Structured exercise improves physical functioning in women with stages I and II breast cancer: results of a randomised controlled trial. J Clin Oncol. 2001;19:657-65.

46. Winters-Stone KM, Dobek J, Bennett JA, Nail LM, Leo MC, Schwartz A. The effect of resistance training on muscle strength and physical function in older, postmenopausal breast cancer survivors: a randomized controlled trial. J Cancer Surviv. 2012;6(2):189-99.

47. Buffart LM, Galvão DA, Brug J, Chinapaw MJM, Newton RU. Evidence-based physical activity guidelines for cancer survivors: current guidelines, knowledge gaps and future research directions. Cancer Treat Rev. 2014;40(2):327-40.

48. Yuen HK, Sword D. Home-based exercise to alleviate fatigue and improve functional capacity among breast cancer survivors. J Allied Health. 2007;36(4):e257-75.

49. Strasser B, Steindorf K, Wiskemann J, Ulrich CM. Impact of resistance training in cancer survivors: a meta-analysis. Med Sci Sports Exerc. 2013:45(11):2080-90.

50. Whitehead S, Lavelle K. Older breast cancer survivors' views and preferences for physical activity. Qual Health Res. 2009;19(7):894-906.

51. Markes M, Brockow T, Resch K. Exercise for women receiving adjuvant therapy for breast cancer. Cochrane Database Syst Rev. 2006;4:CD005001.

52. Mishra SI, Scherer RW, Snyder C, Geigle PM, Berlanstein DR, Topaloglu O. Exercise interventions on health-related quality of life for people with cancer during active treatment. Cochrane Database Syst Rev. 2012;8:CD008465.

53. Daley AJ, Crank H, Saxton JM, Mutrie N, Coleman R, Roalfe A. Randomized trial of exercise therapy in women treated for breast cancer. J Clin Oncol. 2007:25:1713-21.

54. Allgayer H, Nicolaus S, Schreiber S. Decreased interleukin-1 receptor antagonist response following moderate exercise in patients with colorectal carcinoma after primary treatment. Cancer Detect Prev. 2004;28:208-13.

55. Hutnick NA, Williams NI, Kraemer WJ, Orsega-Smith E, Dixon RH, Bleznak AD, et al. Exercise and lymphocyte activation following chemotherapy for breast cancer. Med Sci Sports Exerc. 2005;37:1827-35.

56. Singh MP, Singh $G$, Singh SM. Role of host's antitumor immunity in exercise-dependent regression of murine T-cell lymphoma. Comp Immunol Microbiol Infect Dis. 2005;28:231-48.

57. Meneses-Echávez JF, Ramírez Vélez R, González Jiménez E, Schmidt Río-Valle J, Sánchez Pérez MJ. Exercise training, inflammatory cytokines, and other markers of low-grade inflammation in breast cancer survivors: A systematic review and meta-analysis. J Clin Oncol. 2014;32(26):121.

58. Cheung YT, Lim SR, Ho HK, Chan A. Cytokines as mediators of chemotherapy-associated cognitive changes: current evidence, limitations and directions for future research. PLoS One. 2013;8(12):e81234. 
59. Fairey AS, Courneya KS, Field CJ, Bell GJ, Jones LW, Mackey JR. Randomized controlled trial of exercise and blood immune function in postmenopausal breast cancer survivors. J Appl Physiol (1985). 2005;98(4):1534-40.

60. Jones LW, Eves ND, Peddle CJ, Courneya KS, Haykowsky M, Kumar V, et al. Effects of presurgical exercise training on systemic inflammatory markers among patients with malignant lung lesions. Appl Physiol Nutr Metab. 2009;34(2):197-202.

61. Guinan E, Hussey J, Broderick JM, Lithander FE, O'Donnell D, Kennedy MJ, et al. The effect of aerobic exercise on metabolic and inflammatory markers in breast cancer survivors-a pilot study. Support Care Cancer. 2013;21(7):1983-92.

\section{Submit your next manuscript to BioMed Central} and take full advantage of:

- Convenient online submission

- Thorough peer review

- No space constraints or color figure charges

- Immediate publication on acceptance

- Inclusion in PubMed, CAS, Scopus and Google Scholar

- Research which is freely available for redistribution 